\title{
The First Chromosome Analysis and Localization of the Nucleolar Organizer Region of Phayre's Flying Squirrel, Hylopetes phayrei (Rodentia, Sciuridae) in Thailand
}

\author{
Sitthisak Jantarat ${ }^{1,2}$, Sumpars Khunsook ${ }^{1}$, Praween Supanuam ${ }^{1,5}$, \\ Somsak Jeewattana ${ }^{3}$, Sarawut Kaewsri ${ }^{4}$, and Alongklod Tanomtong ${ }^{1 *}$ \\ ${ }^{1}$ Genetics and Environmental Toxicology Research Group, Department of Biology, \\ Faculty of Science, Khon Kaen University, Muang, Khon Kaen 40002, Thailand \\ ${ }^{2}$ Biology Program, Faculty of Science and Technology, Prince of Songkla University, \\ Muang, Pattani 94000, Thailand \\ ${ }^{3}$ Program in Computer Science, Faculty of Science, Buriram Rajabhat University, \\ Muang, Buriram 31000, Thailand \\ ${ }^{4}$ Program in Applied Biology, Faculty of Science, Buriram Rajabhat University, \\ Muang, Buriram 31000, Thailand \\ ${ }^{5}$ Biology Program, Faculty of Science, Ubonratchathani Rajabhat University, \\ Ubon Ratchathani, Muang 34000, Thailand
}

Received November 6, 2012; accepted March 20, 2013

\begin{abstract}
Summary We report the first chromosome analysis and localization of the nucleolar organizer region of the Phayre's flying squirrel, Hylopetes phayrei (Blyth, 1985) from Thailand. After standard peripheral blood lymphocytes had been cultured at $37^{\circ} \mathrm{C}$ for $96 \mathrm{~h}$ in the presence of colchicine, the metaphase spreads were performed on microscopic slides and air-dried. Conventional staining, GTG-banding, high-resolution and Ag-NOR staining techniques were applied to stain the chromosomes. The results showed that the diploid chromosome number of $H$. phayrei was $2 n=38$ and the fundamental number (NF) were 76 in both males and females. The karyotype has the presence of 2 large metacentric, 8 large submetacentric, 8 large acrocentric, 6 medium acrocentric, 6 small metacentric and 6 small acrocentric chromosomes. The $\mathrm{X}$ chromosome is a small submetacentric chromosome and the $\mathrm{Y}$ chromosome is a small acrocentric chromosome. From the GTG-banding and high-resolution techniques, the numbers of bands and locations in the $H$. phayrei are 182 and 234, respectively; each chromosome pair could be clearly differentiated. The Ag-NOR staining demonstrated that the three pairs of nucleolar organizer regions (NORs) were observed on the long arm regions of chromosome pairs 1,5 , and 14 . The karyotype formula of $H$. phayrei could be deduced as:
\end{abstract}

$2 n$ (diploid) $38=\mathrm{L}_{2}^{\mathrm{m}}+\mathrm{L}_{8}^{\mathrm{sm}}+\mathrm{L}_{8}^{\mathrm{a}}+\mathrm{M}_{6}^{\mathrm{a}}+\mathrm{S}_{6}^{\mathrm{m}}+\mathrm{S}_{6}^{\mathrm{a}}+$ sex-chromosomes

Key words Hylopetes phayrei, Karyotype, Chromosome, Nucleolar organizer region.

Flying squirrels (Petauristinae, Sciuridae, Rodentia) are members of rodents that can make gliding leaps by means of the patagium (parachute-like membrane) connected on each side to their forelegs and hind legs. They are found in North America, Europe and Asia, including at least 37 species grouped into 15 genera. Flying squirrels are special in their life history characteristics. They are nocturnal gliders and hide in holes or leaf drays during the daytime (Nowak 1991). The flying squirrel consists of six genera and 12 species in Thailand, namely, the lesser giant flying squirrel (Petaurista elegans), red giant flying squirrel (Peta. petaurista), Indian giant flying squirrel (Peta.

*Corresponding author, e-mail: tanomtong@hotmail.com

DOI: $10.1508 /$ cytologia.79.3 
Table 1. Review of flying squirrel cytogenetic reports in the subfamily Petauristinae (genera; Petaurista, Pteromys, Belomys, Hylopetes and Glaucomys).

\begin{tabular}{|c|c|c|c|c|c|c|}
\hline Species & $2 n$ & $\begin{array}{l}\text { Karyotype } \\
\text { formula }\end{array}$ & $\mathrm{NF}$ & Sex chromosome & NOR-banded & Reference \\
\hline Pe.petaurista & 38 & $12 m+24 s m+2 a$ & 76 & - & - & Nadler and Lay (1971) \\
\hline Pe. petaurista melanotus & 38 & $22 \mathrm{~m}+14 \mathrm{sm}$ & 76 & $\mathrm{X}(-), \mathrm{Y}(\mathrm{a})$ & $16,17(\mathrm{TR})$ & Oshida et al. (1992) \\
\hline Pe. petaurista grandis & 38 & $22 m+14 s m$ & 76 & $\mathrm{X}(-), \mathrm{Y}(\mathrm{a})$ & $7,17(\mathrm{TR})$ & Oshida et al. (1992) \\
\hline Pe. alborufus castaneus & 38 & $12 m+24 s m$ & 76 & $\mathrm{X}(\mathrm{sm}), \mathrm{Y}(\mathrm{a})$ & 8,13 (SCR, TR) & Oshida et al. (2000a) \\
\hline \multirow[t]{2}{*}{ Pe. alborufus lena } & 38 & $22 m+14 s m$ & 76 & $\mathrm{X}(\mathrm{m}), \mathrm{Y}(\mathrm{a})$ & $16(\mathrm{TR})$ & Oshida et al. (2000a) \\
\hline & 38 & $22 \mathrm{~m}+14 \mathrm{sm}$ & 76 & $\mathrm{X}(-), \mathrm{Y}(\mathrm{a})$ & $16,17(\mathrm{TR})$ & Oshida et al. (1992) \\
\hline \multirow[t]{2}{*}{ Pe. leucogenys } & 38 & $22 \mathrm{~m}+14 \mathrm{sm}$ & 76 & $\mathrm{X}(\mathrm{m}), \mathrm{Y}(\mathrm{a})$ & - & Oshida and Obara (1993) \\
\hline & - & - & - & - & $1,8,16(\mathrm{TR})$ & Oshida and Yoshida (1999) \\
\hline Pe. magnificus & 38 & $18 \mathrm{~m}+16 \mathrm{sm}+2 \mathrm{a}$ & - & $\mathrm{X}(\mathrm{m}), \mathrm{Y}(\mathrm{t})$ & - & $\begin{array}{l}\text { Chatterjee and Majhi } \\
\text { (1975) }\end{array}$ \\
\hline Pe. albiventer & 38 & - & - & - & - & O’Brien et al. (2006) \\
\hline \multirow[t]{3}{*}{ Pt. volans } & 38 & $12 \mathrm{~m}+22 \mathrm{sm}+2 \mathrm{a}$ & 76 & $\mathrm{X}(\mathrm{sm}), \mathrm{Y}(\mathrm{a})$ & - & Rausch and Rausch (1982) \\
\hline & 38 & $10 \mathrm{~m}+22 \mathrm{sm}+4 \mathrm{t}$ & 68 & $\mathrm{X}(\mathrm{sm}), \mathrm{Y}(\mathrm{a})$ & $17(\mathrm{TR})$ & Oshida et al. (2000b) \\
\hline & - & - & - & - & $17(\mathrm{TR})$ & Oshida and Yoshida (1999) \\
\hline \multirow[t]{2}{*}{ Pt. momonga } & 38 & $8 m+6 s m+18 a+4 t$ & 68 & $\mathrm{X}(\mathrm{sm}), \mathrm{Y}(\mathrm{a})$ & $5(\mathrm{STR})$ & Oshida et al. (2000b) \\
\hline & - & - & - & - & $5(\mathrm{STR})$ & Oshida and Yoshida (1999) \\
\hline B. pearsonii & 38 & $12 \mathrm{~m}+24 \mathrm{sm}$ & 76 & $X(m), Y(a)$ & $1(\mathrm{TR})$ & Oshida et al. (2002) \\
\hline H. alboniger alboniger & 38 & - & 76 & - & - & Gray and Sharma (1972) \\
\hline H. phayrei & 38 & $8 m+8 s m+20 a$ & 76 & $\mathrm{X}(\mathrm{sm}), \mathrm{Y}(\mathrm{a})$ & $1,5,14(\mathrm{SCR}, \mathrm{STR})$ & Present study \\
\hline \multirow[t]{2}{*}{ G. sabrinus laseivus } & 48 & - & 74 & - & - & Nadler and Sutton (1967) \\
\hline & 48 & - & 80 & - & - & Schindler et al. (1973) \\
\hline G. volans & 48 & - & - & - & - & Nadler and Sutton (1967) \\
\hline
\end{tabular}

Remarks: $2 n=$ diploid chromosome number, $\mathrm{NF}=$ fundamental number (number of chromosome arm), $\mathrm{m}=$ metacentric, $\mathrm{sm}=$ submetacentric, $\mathrm{a}=$ acrocentric, $\mathrm{t}=$ telocentric, $\mathrm{X}=\mathrm{X}$-chromosome, $\mathrm{Y}=\mathrm{Y}$-chromosome, $\mathrm{STR}=$ subtelocentric region, $\mathrm{SCR}=$ subcentromeric region, $\mathrm{TR}=$ telomeric region and $-=$ not available.

philippensis), large black flying squirrel (Aeromys tephromelas), Phayre's flying squirrel (Hylopetes phayrei), Parti-coloured flying squirrel (H. alboniger), red-cheeked flying squirrel (H. spadiceus), grey-cheeked flying squirrel (H. lepidus), white-bellied flying squirrel (Petinomys setosus), Vordermann's flying squirrel (Peti. vordermanni), hair-fooded flying squirrel (Belomys pearsonii) and smoky flying squirrel (Pteromyscus pulverulentus) (Lekagul and McNeely 1988).

Although phylogenetic studies have been performed paleontologically, morphologically, and molecular biologically, cytogenetic data with banding patterns for these flying squirrel species are still somewhat limited. This paucity of data cannot provide discussion of the karyotypic evolution between flying and non-flying squirrels. However, several studies have appeared dealing with banded karyotypes in several species of the subfamily Petauristinae (Rausch and Rausch 1982, Oshida et al. 1992, 2000a, 2000b, 2002, Oshida and Obara 1993, Oshida and Yoshida 1999). There is only one previous report on the genus Hylopetes. Gray and Sharma (1972) demonstrated by a conventional staining technique that $H$. alboniger alboniger's karyotype is $2 n$ (diploid) $=38$ and the fundamental number (NF) is 76 (Table 1).

In this report, the chromosomal characteristics of $H$. phayrei (Fig. 1) from Thailand are preliminary presented along with the chromosomal localizations of the nucleolar organizer regions (NORs). Several studies have demonstrated variations in the chromosomal localization of NORs, including those of vertebrates using silver staining (Ag-NOR banding technique), which provided useful information of karyotypic evolution (Volleth 1987, Ono and Obara 1994, Mandahl 1979, Winking et al. 1980, Shida et al. 1999). The number of Ag-NORs was influenced by the activity of rRNA transcription (Babu and Verma 1985, Ono and Yoshida 1998). Also, comparing previous reports of the chromosomes of $H$. phayrei and those of other flying squirrel species, the 


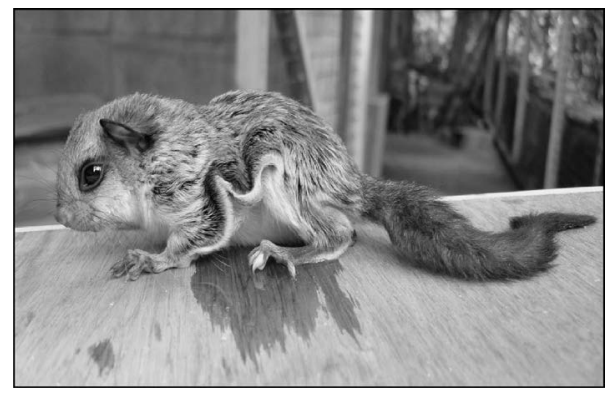

Fig. 1. General characteristic of the Phayre's flying squirrel, Hylopetes phayrei (Rodentia, Sciuridae) from Thailand.

phylogenetic position of $H$. phayrei within the flying squirrels is only briefly referred to.

\section{Materials and methods}

Blood samples from the femoral vein were collected from three males and three females, which were kept in Mahasarakham Province, Thailand using aseptic technique. The samples were kept in $5 \mathrm{~mL}$ vacuum tubes containing heparin to prevent blood clotting and were cooled on ice until arriving at the laboratory.

\section{Cell preparation}

The lymphocytes were cultured using the peripheral blood microculture technique adapted from Moorhead et al. (1960) and Rooney (2001).

Cell culture: The RPMI 1640 medium was prepared with 2\% PHA (Phytohemagglutinin) as a mitogen and kept in blood culture bottles of $5 \mathrm{~mL}$ each. A blood sample of $0.5 \mathrm{~mL}$ was dropped into a medium bottle, mixed, loosely capped, incubated at $37^{\circ} \mathrm{C}$ under a $5 \%$ carbon dioxide environment and regularly shaken in the morning and evening. When reaching harvest time at $72 \mathrm{~h}$ of incubation, colchicine was introduced and well mixed, followed by further incubation for $30 \mathrm{~min}$.

Cell harvest: The blood sample mixture was centrifuged at $1,200 \mathrm{rpm}$ for $10 \mathrm{~min}$ and the supernatant was discarded. Ten milliliters of hypotonic solution $(0.075 \mathrm{M} \mathrm{KCl})$ was applied to the pellet and the mixture was incubated for $30 \mathrm{~min}$. $\mathrm{KCl}$ was discarded with the supernatant after centrifugation again at $1,200 \mathrm{rpm}$ for $10 \mathrm{~min}$. Cells were fixed by fresh, cold fixative (methanol: glacial acetic acid $=3: 1$ ) gradually added up to $8 \mathrm{~mL}$ before centrifuging again at 1,200 rpm for 10 min, and the supernatant was discarded. The fixation was repeated until the supernatant was clear and the pellet was mixed with $1 \mathrm{~mL}$ of fixative. The mixture was dropped onto a clean and cold slide using a micropipette followed by the air-drying technique. The slide was conventionally stained with $20 \%$ stock Giemsa's solution for $30 \mathrm{~min}$.

\section{GTG-banding technique}

The GTG-banding technique was adapted from Campiranont (2003). The slide was well dried and then soaked in working trypsin $\left(0.025 \%\right.$ trypsin EDTA) at $37^{\circ} \mathrm{C}$ before terminating trypsin activity by washing the slide with Sorensen buffer. The slide was stained with $20 \%$ Giemsa's solution for $30 \mathrm{~min}$.

\section{High-resolution technique}

The high-resolution technique was adapted from Rooney (2001). After the lymphocytes were cultured for $72 \mathrm{~h}, 0.05 \mathrm{~mL}$ of $10^{-5} \mathrm{M}$ methotrexate was applied into the cultured lymphocytes to 


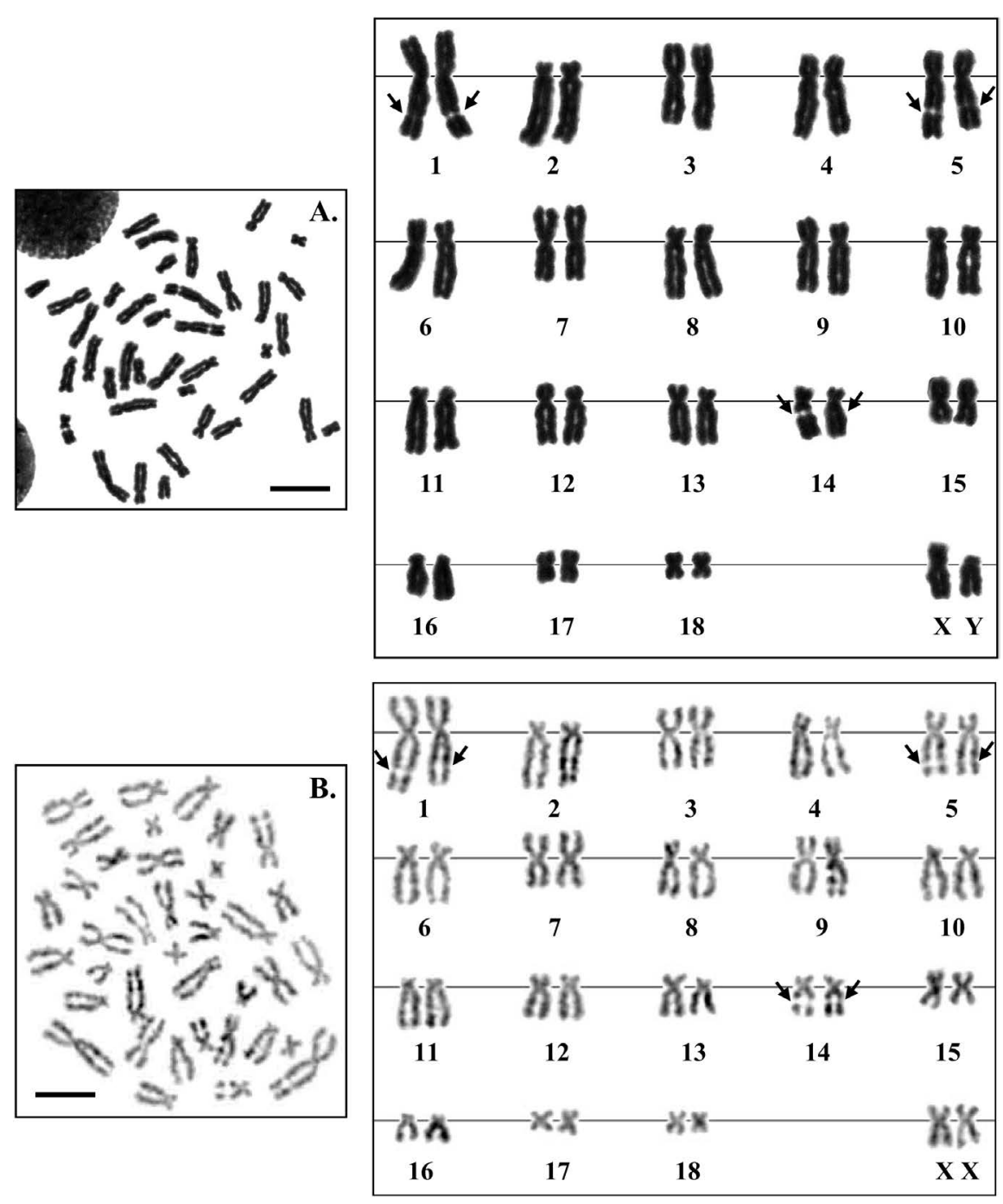

Fig. 2. Metaphase chromosome plates and karyotypes of male (A.) and female (B.) Phayre's flying squirrel (Hylopetes phayrei) $2 n=38$ by conventional staining technique. Arrows indicate satellite chromosomes/ NORs (scale bars $10 \mu \mathrm{m}$ ).

induce synchronization. The mixture was incubated again for $17 \mathrm{~h}$ before the methotrexate was discarded with the supernatant by centrifuging at $2,800 \mathrm{rpm}$. The pellet was mixed with $5 \mathrm{~mL}$ of the RPMI 1,640 medium and centrifuged at 2,800 rpm. The supernatant was discarded before the cultured cells were released by adding $0.2 \mathrm{~mL}$ thymidine and incubated for $5 \mathrm{~h}$ and $15 \mathrm{~min}$. The cells were harvested at the exact time and stained by using GTG-banding procedure.

\section{Ag-NOR banding technique}

The Ag-NOR banding technique was conducted (Howell and Black 1980) by adding two drops of $50 \%$ silver nitrate and $2 \%$ gelatin on slides, respectively. The slides were then sealed with cover glasses and incubated at $60^{\circ} \mathrm{C}$ for $5 \mathrm{~min}$. After that, the slides were soaked in distilled water until the cover glasses were separated. The slide was stained with $20 \%$ Giemsa's solution for 1 min. 


\section{Chromosomal checks, karyotyping and idiograming}

Chromosome counting was performed on mitotic metaphase cells under a light microscope. Twenty clearly observable and well-spread chromosomes of each male and female were selected and photographed. The length of short arm chromosome (Ls) and the length of long arm chromosome (Ll) were measured and the length of total arm chromosome (LT, LT=Ls $+\mathrm{Ll}$ ) was calculated. The relative length (RL), the centromeric index (CI) and their standard deviation (SD) were estimated (Chaiyasut 1989). The CI (q/p+q) between $0.50-0.59,0.60-0.69,0.70-0.89$ and 0.90-0.99 were described as metacentric, submetacentric, acrocentric and telocentric chromosomes, respectively. The fundamental number (number of chromosome arm, NF) was obtained by assigning a value of two to metacentric, submetacentric and acrocentric chromosomes, and a value of one to telocentric chromosomes. All parameters were used in karyotyping and idiograming.

\section{Results and discussion}

No significant intra-individual variation in chromosome constitution, banding pattern, and chromosome number was observed in any of the specimens examined. The diploid chromosome number $(2 n)$ was found to be 38 and the fundamental number (NF) 76 in each specimen. Its karyotype was characterized by bi-armed chromosomes. The X-chromosome and Y-chromosome were small among the chromosome complements. The relative lengths of the X-chromosome and Y-chromosome were $0.022 \pm 0.001$ and $0.016 \pm 0.002$, respectively.

\section{Conventional staining karyotype}

The cytogenetic study of $H$. phayrei using lymphocyte culture and the conventional staining procedures revealed that the chromosome number was $2 n$ (diploid) $=38$, which consists of 36 (18 pairs) autosomes and two (1 pair) sex-chromosomes. The NF of $H$. phayrei was 76 in both males and females. According to Gray and Sharma (1972), who reported the chromosome number and NF of $H$. alboniger alboniger to be 38 and 76, respectively, the chromosome number and NF of flying squirrel species in the genus Hylopetes are all the same, and our reults agree. The karyotype of $H$. phayrei was composed of 2 large metacentric, 8 large submetacentric, 8 large acrocentric, 6 medium acrocentric, 6 small metacentric and 6 small acrocentric chromosomes (Fig. 2). Cytogenetic studies on the flying squirrel are few. Fourteen species have been studied cytogenetically, each having the same diploid number $(2 n=38)$ (Nadler and Lay 1971, Gray and Sharma 1972, Chatterjee and Majhi 1975, Oshida et al. 1992, 2000a, 2000b, 2002, Oshida and Obara 1993, Rausch and Rausch 1982, Oshida and Yoshida 1999, O’Brien et al. 2006). In some species, a different diploid number from these studies has been reported, such as $2 n=48$ for Glaucomys sabrinus laseivus and G. volans (Nadler and Sutton 1967, Schindler et al. 1973).

\section{Ag-NOR banded karyotype}

Our cytogenetic study of $H$. phayrei performed by Ag-NOR staining technique is the first of its kind. The objective of this technique is to detect the nucleolar organizer regions (NORs) (satellite chromosome), which represent the location of genes that function in ribosome synthesis (18S and 28S ribosomal RNA). NORs produce numerous gene expressions, and they are composed of more non-histone protein than other chromosome regions. These proteins induce specific dark bands by the reduction of organic silver that changes silver to be dark (Gold et al. 1990). In $H$. phayrei, Ag-NOR bands were observed on the satellite stalk and the subtelomeric regions of the long arm of the chromosome pairs 1 and 5 (four positions), and the subcentromeric regions of the long arm of the chromosome pair 14 (two positions) (Fig. 3).

Twelve species of flying squirrels have been investigated by the Ag-NOR staining technique, some of which have been applied to elucidate taxonomic and morphological affinities, e.g. in the 

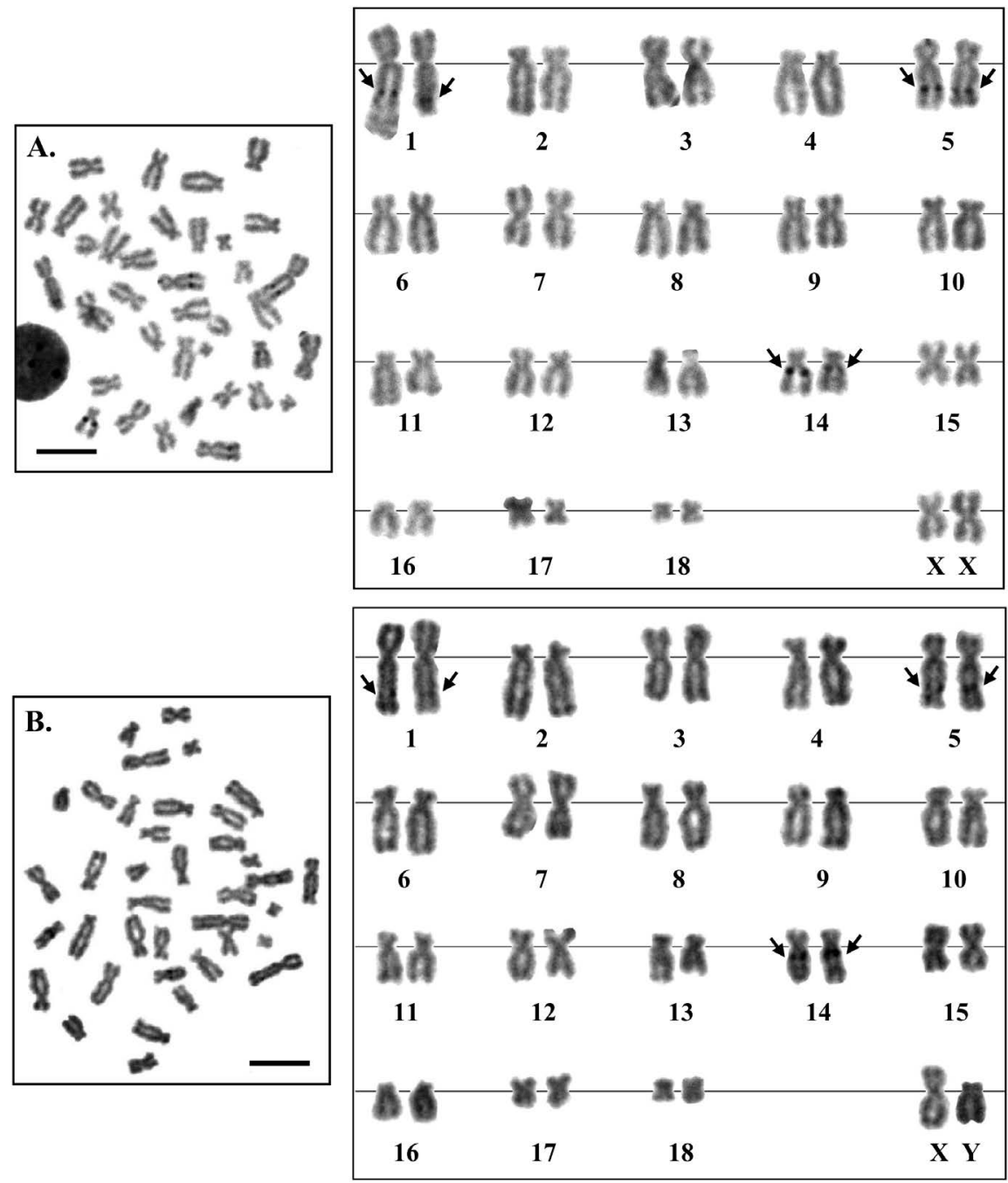

Fig. 3. Metaphase chromosome plates and karyotypes of female (A.) and male (B.) Phayre's flying squirrel (Hylopetes phayrei) $2 n=38$ by Ag-NOR banding technique. Arrows indicate nucleolar organizer regions/NORs (scale bars $10 \mu \mathrm{m}$ ).

genus Petaurista (Oshida et al. 1992, 2000a, Oshida and Yoshida 1999). Moreover, the amount and location of NORs can explain the evolution of each chromosome. Normally, most flying squirrels (genera Petaurista, Pteromys and Belomys) have one to two pairs of small NORs in a chromosome complement. If some flying squirrel (genus Hylopetes) has more than four NORs, it may have been caused by a translocation between a NOR containing chromosome and another chromosome. Furthermore, NORs are usually located close to a telomere of a chromosome arm. If a NOR appears between a centromere and a telomere, it may be caused by the centric fusion or pericentric inversion between two telocentric chromosomes.

\section{GTG-banded and high-resolution karyotype}

The GTG-banding and high-resolution techniques provide a clear chromosome band, which are represented by positive-black regions (heterochromatin) and negative-white regions (euchromatin) on autosomes and sex-chromosomes. The GTG-banding revealed that the number of 

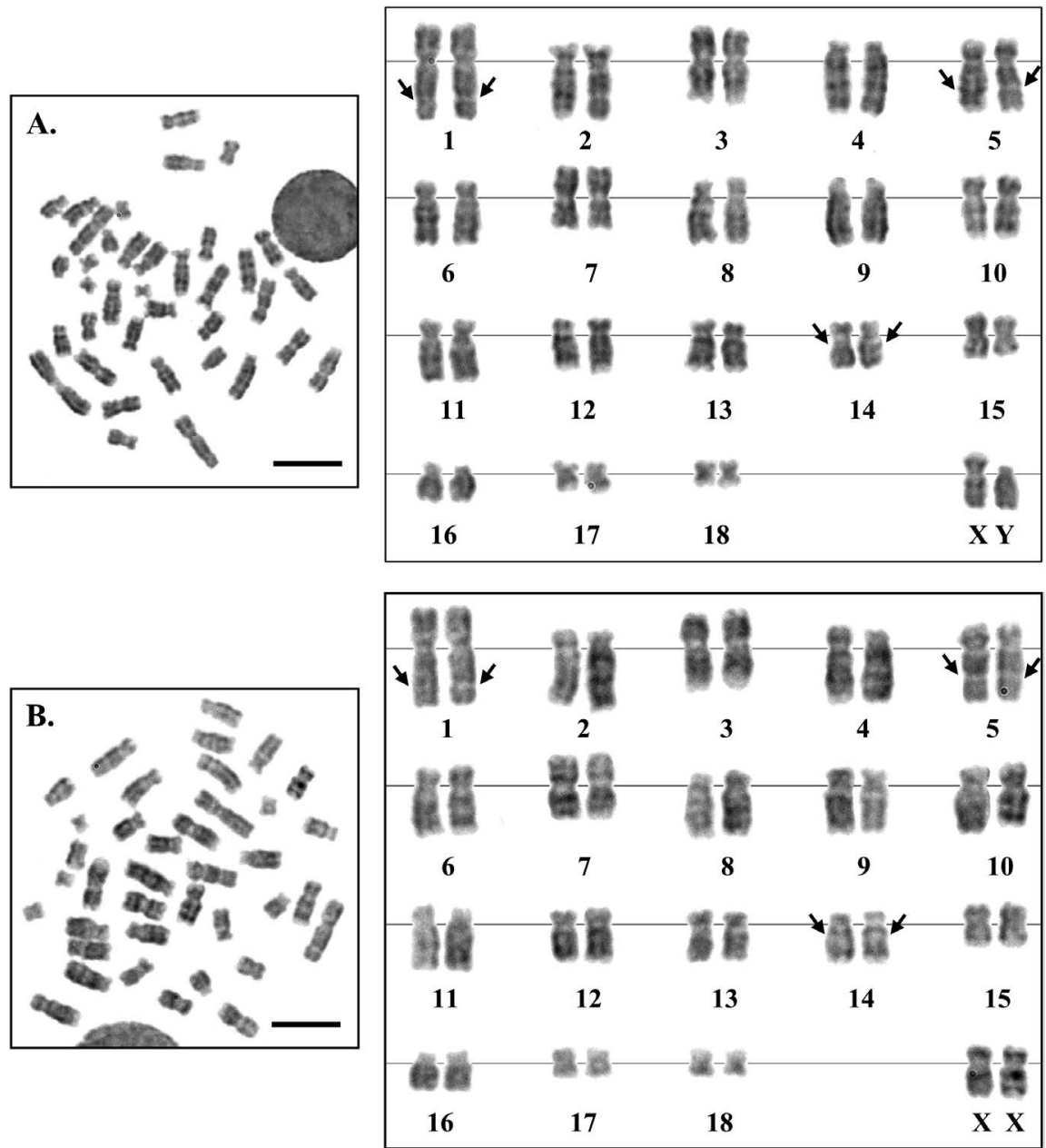

Fig. 4. Metaphase chromosome plates and karyotypes of male (A.) and female (B.) Phayre's flying squirrel (Hylopetes phayrei) $2 n=38$ by GTG-banding banding technique. Arrows indicate nucleolar organizer regions/NORs (scale bars $10 \mu \mathrm{m}$ ).

G-bands on one set of haploid chromosomes (n), which includes autosomes and the $\mathrm{X}$ and $\mathrm{Y}$ chromosomes is 182 bands for the H. phayrei. The number of bands in one set of prometaphase haploid chromosomes from the high-resolution technique is 234 bands (Figs. 4 and 5). Stanyon (1987) suggested that the high-resolution technique provides high efficiency for chromosome difference comparison. The evolution study of gorillas, orangutans, chimpanzees and humans by the comparison of chromosome structure and chromosome bands with GTG-banding and highresolution techniques gave chromosome band numbers of 320-500 and over 1,000 bands per haploid set (Yunis and Prakash 1982). In this study, the chromosome scoring is done with only clearly visible bands except for the variable band due to the small number of scored bands.

The high-resolution technique provides the possibility to detect chromosome breaks and rearrangement events within major bands. The developments in cell culture and banding techniques have been extremely fast; 10 years after the Paris Conference in 1971, Yunis (1981) published the haploid human karyotype at the 1,700-band stage. For other mammals, the development was slower, but recently, good results have narrowed the gap between human and animal cytogenetics. However, the increase of bands in a given karyotype is not an aim by itself, but a research tool, so 

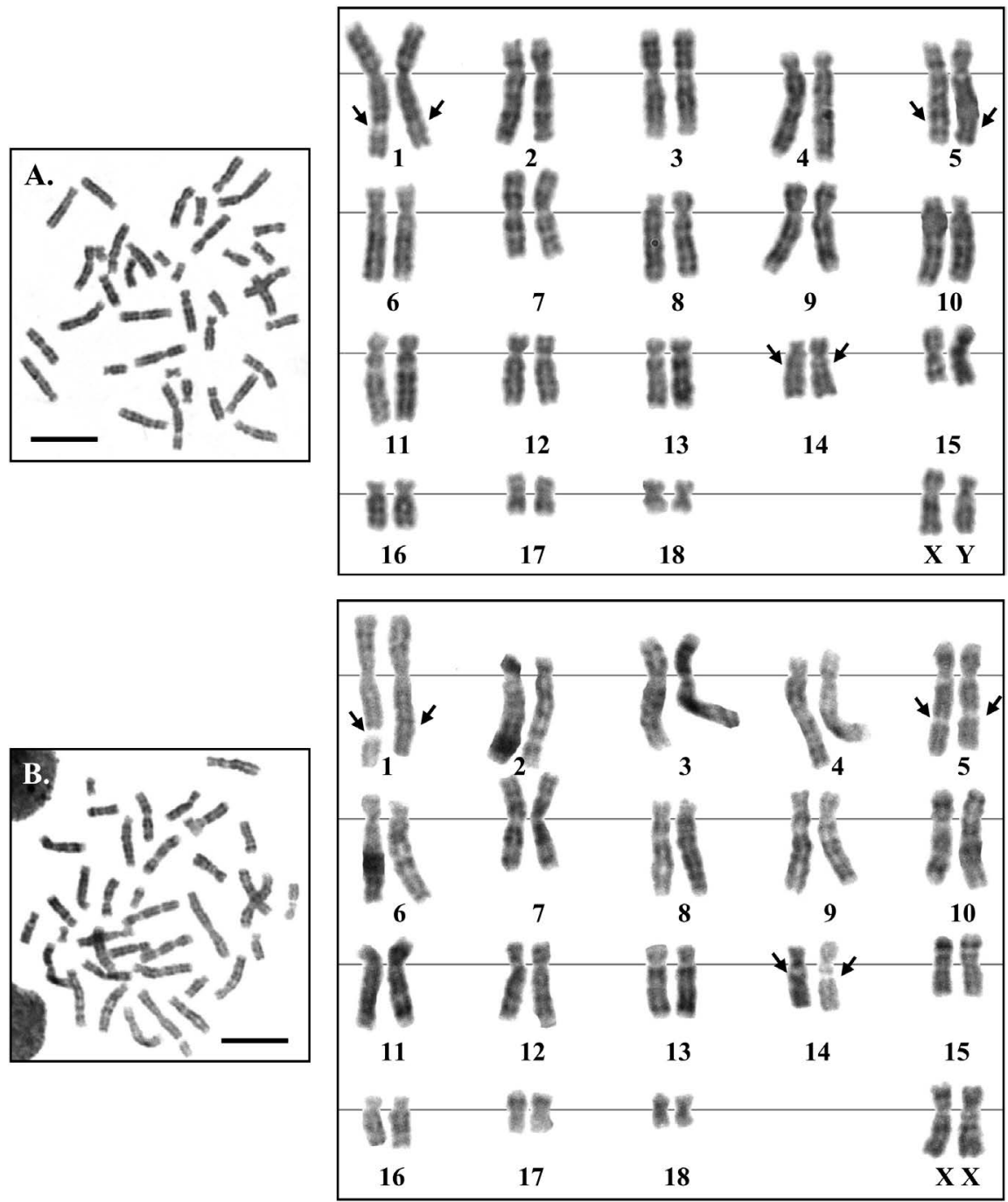

Fig. 5. Prometaphase chromosome plates and karyotypes of male (A.) and female (B.) Phayre's flying squirrel (Hylopetes phayrei) $2 n=38$ by high-resolution technique. Arrows indicate nucleolar organizer regions/NORs (scale bars $10 \mu \mathrm{m}$ ).

the value of a high band level is reduced if band quality is sacrificed in the process. When highresolution banding is combined with other chromosomal techniques, specific sites on the chromosomes can be detected and precisely localized. The high-resolution technique has been extremely valuable, especially for the localization of single copy genes and specific breakpoints (Rønne 1991).

\section{Chromosome markers}

For $H$. phayrei, chromosome markers are the autosome pair 1 and pair 21 , which are the largest submetacentric chromosome and the smallest metacentric chromosome, respectively. The important karyotype feature of $H$. phayrei is the asymmetrical karyotypes, which were found in all three types of chromosomes (metacentric, submetacentric and acrocentric chromosomes). The largest chromosome is four times larger than the smallest chromosomes. Figures 6-9 show the idiogram of the H. phayrei from conventional staining, Ag-NOR banding, GTG-banding and high- 


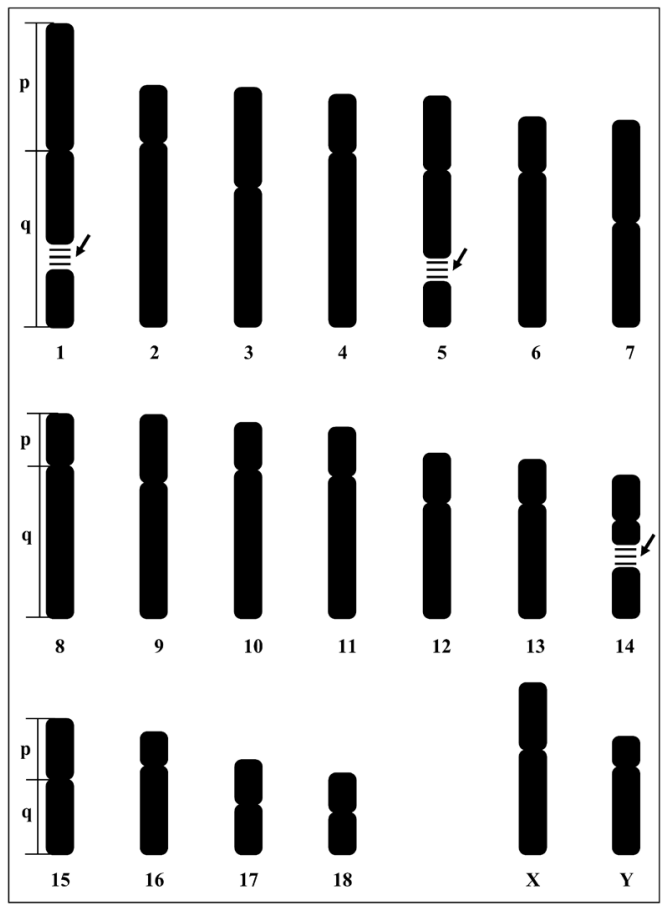

Fig. 6. Idiogram of Phayre's flying squirrel (Hylopetes phayrei) $2 n=38$ by conventional staining. Arrows indicate nucleolar organizer regions (NORs).

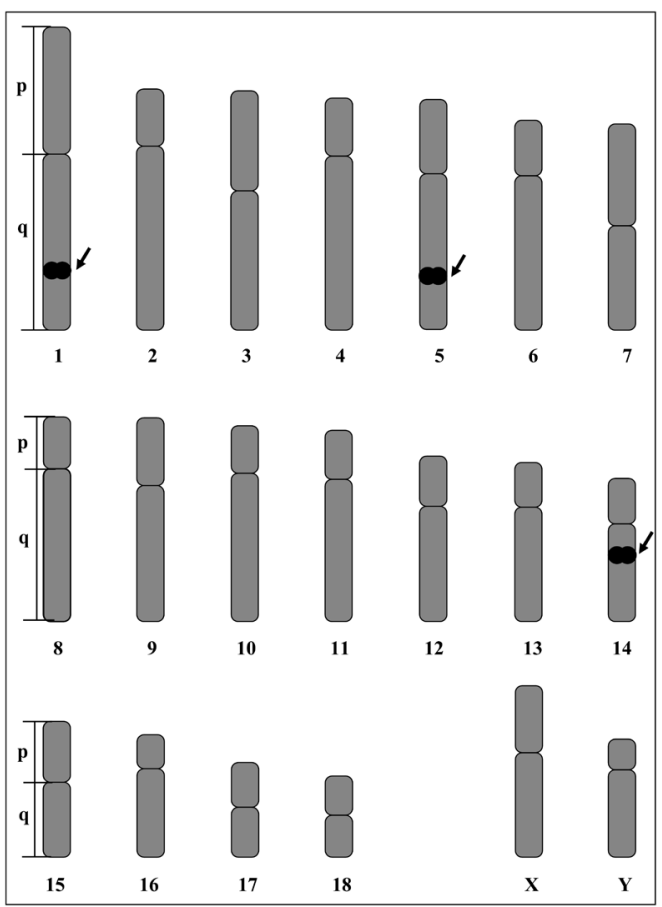

Fig. 7. Idiogram of Phayre's flying squirrel (Hylopetes phayrei) $2 n=38$ by Ag-NOR banding technique. Arrows indicate nucleolar organizer regions (NORs). 


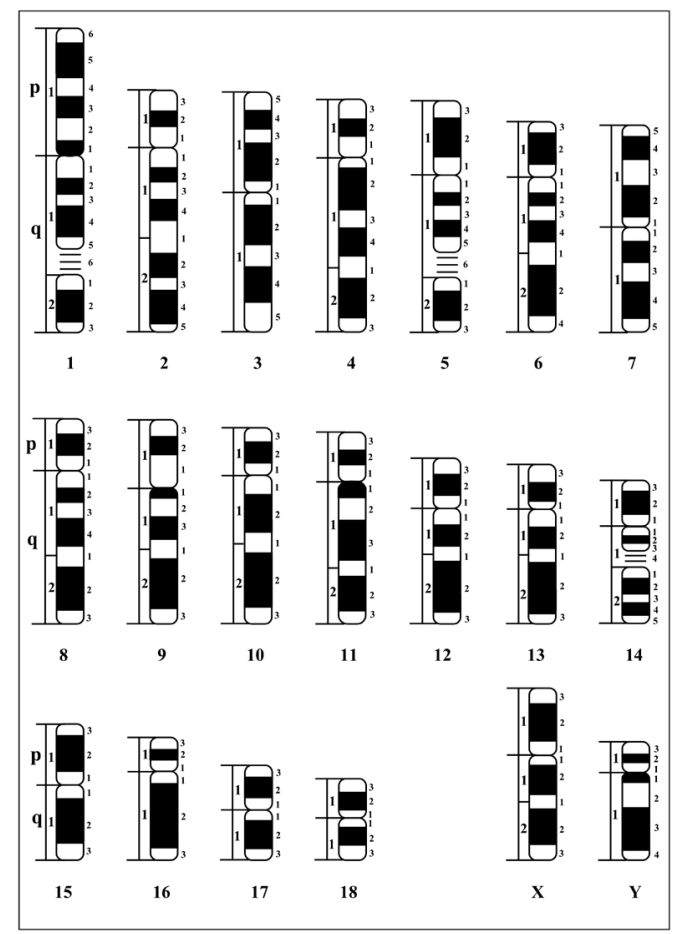

Fig. 8. Idiogram of Phayre's flying squirrel (Hylopetes phayrei) $2 n=38$ by GTG-banding technique. Arrows indicate nucleolar organizer regions (NORs).

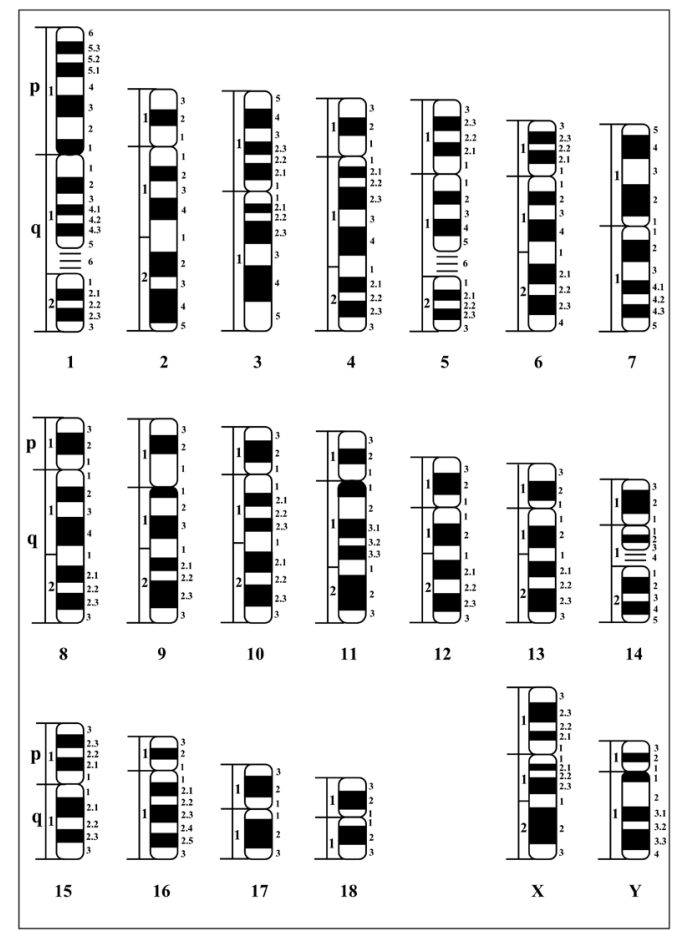

Fig. 9. Idiogram of Phayre's flying squirrel (Hylopetes phayrei) $2 n=38$ by high-resolution technique. Arrows indicate nucleolar organizer regions (NORs). 
Table 2. Mean lengths of short arm chromosome (Ls), long arm chromosome (Ll), and total arm chromosome (LT), relative length (RL), centromeric index (CI), and standard deviation of RL and CI from 20 metaphases of male and female Phayre's flying squirrel (Hylopetes phayrei), $2 n=38$.

\begin{tabular}{ccrccccc}
\hline \hline $\begin{array}{c}\text { Chromosome } \\
\text { pair }\end{array}$ & Ls & L1 & LT & CI \pm SD & RL \pm SD & $\begin{array}{c}\text { Chromosome } \\
\text { size }\end{array}$ & $\begin{array}{c}\text { Chromosome } \\
\text { type }\end{array}$ \\
\hline $1^{*}$ & 74.340 & 113.499 & 187.838 & $0.604 \pm 0.020$ & $0.045 \pm 0.002$ & Large & Submetacentric \\
2 & 32.549 & 115.782 & 148.331 & $0.779 \pm 0.123$ & $0.035 \pm 0.004$ & Large & Acrocentric \\
3 & 57.174 & 87.293 & 144.467 & $0.603 \pm 0.026$ & $0.034 \pm 0.002$ & Large & Submetacentric \\
4 & 33.955 & 108.557 & 142.511 & $0.760 \pm 0.105$ & $0.034 \pm 0.002$ & Large & Acrocentric \\
$5^{*}$ & 42.971 & 96.328 & 139.299 & $0.692 \pm 0.033$ & $0.033 \pm 0.002$ & Large & Submetacentric \\
6 & 31.836 & 96.232 & 128.067 & $0.751 \pm 0.061$ & $0.030 \pm 0.002$ & Large & Acrocentric \\
7 & 58.838 & 64.816 & 123.653 & $0.524 \pm 0.018$ & $0.029 \pm 0.002$ & Large & Metacentric \\
8 & 29.127 & 93.837 & 122.963 & $0.758 \pm 0.081$ & $0.029 \pm 0.001$ & Large & Acrocentric \\
9 & 40.217 & 82.351 & 122.568 & $0.675 \pm 0.062$ & $0.029 \pm 0.001$ & Large & Submetacentric \\
10 & 25.566 & 89.413 & 114.942 & $0.776 \pm 0.058$ & $0.027 \pm 0.003$ & Medium & Acrocentric \\
11 & 28.033 & 85.999 & 113.541 & $0.763 \pm 0.137$ & $0.027 \pm 0.003$ & Medium & Acrocentric \\
12 & 28.449 & 71.152 & 99.143 & $0.720 \pm 0.062$ & $0.024 \pm 0.001$ & Medium & Acrocentric \\
13 & 23.842 & 69.809 & 93.518 & $0.745 \pm 0.035$ & $0.022 \pm 0.002$ & Small & Acrocentric \\
$14 *$ & 23.266 & 64.281 & 86.979 & $0.741 \pm 0.070$ & $0.021 \pm 0.002$ & Small & Acrocentric \\
15 & 37.648 & 42.939 & 80.187 & $0.537 \pm 0.065$ & $0.019 \pm 0.001$ & Small & Metacentric \\
16 & 19.454 & 54.370 & 73.209 & $0.745 \pm 0.047$ & $0.017 \pm 0.003$ & Small & Acrocentric \\
17 & 26.366 & 30.059 & 56.345 & $0.534 \pm 0.032$ & $0.013 \pm 0.001$ & Small & Metacentric \\
18 & 20.918 & 23.225 & 44.143 & $0.527 \pm 0.030$ & $0.011 \pm 0.002$ & Small & Metacentric \\
$\mathrm{X}$ & 34.755 & 57.828 & 92.583 & $0.627 \pm 0.032$ & $0.022 \pm 0.001$ & Small & Submetacentric \\
$\mathrm{Y}$ & 17.822 & 50.651 & 68.473 & $0.738 \pm 0.027$ & $0.016 \pm 0.002$ & Small & Acrocentric \\
\hline
\end{tabular}

Remark: *=NOR-bearing chromosomes (satellite chromosomes).

resolution techniques, respectively. The idiogram shows a gradually decreasing length of the chromosomes. The chromosome length in centimeters of 20 cells (males and females) in mitotic metaphase was measured. The mean length of short arm chromosome (Ls), length of long arm chromosome (Ll), total length of arm chromosome (LT), relative length (RL), centromeric index (CI), standard deviation of RL and CI, and the size and type of chromosomes are shown in Table 2. The karyotype formula for $H$. phayrei could be deduced as:

$2 n$ (diploid) $38=\mathrm{L}_{2}^{\mathrm{m}}+\mathrm{L}_{8}^{\mathrm{sm}}+\mathrm{L}_{8}^{\mathrm{a}}+\mathrm{M}_{6}^{\mathrm{a}}+\mathrm{S}_{6}^{\mathrm{m}}+\mathrm{S}_{6}^{\mathrm{a}}+$ sex-chromosomes

\section{Acknowledgments}

This work was financially supported in part by a full scholarship from the Ministry of Science and Technology (MOST) and Genetics and Environmental Toxicology Research Group, Khon Kaen University.

\section{References}

Babu, K. A., and Verma, R. S. 1985. Structural and functional aspects of nucleolar organizer regions (NORs) of human chromosomes. Int. Rev. Cytol. 94: 151-176.

Campiranont, A. 2003. Cytogenetics. 2nd edition. Department of Genetics, Faculty of Science, Kasetsart University, Bangkok.

Chaiyasut, K. 1989. Cytogenetics and Cytotaxonomy of the Family Zephyranthes. Department of Botany, Faculty of Science, Chulalongkorn University, Bangkok. pp. 119-178.

Chatterjee, K., and Majhi, A. 1975. Chromosomes of the Himalayan flying squirrel Petaurista magnificus. Mammalia 39: $447-450$.

Gold, J. R., Li, Y. C., Shipley, J. R., Shipley, N. S., and Powers, P. K. 1990. Improved methods for working with fish chromosomes with a review of metaphase chromosome banding. J. Fish Biol. 37: 563-575.

Gray, T. S., and Sharma, T. 1972. Chromosomes of the flying squirrel Hylopetes a. alboniger (Hodgson). Indian Biologist 
4: $45-49$.

Howell, W. M., and Black, D. A. 1980. Controlled silver-staining of nucleolus organizer regions with a protective colloidal developer: a 1-step method. Experientia 36: 1014-1015.

Lekagul, B., and McNeely, J. A. 1988. Mammals of Thailand. 2nd edition. Sahakarn Bhaet, Bangkok.

Mandahl, N. 1979. Localization of nucleolar organizer regions in European hedgehogs (Insectivora, Mammalia). Heretites 91: $149-161$.

Moorhead, P. S., Nowell, P. C., Nellman, W. J., Battips, D. M., and Hungerford, D. A. 1960. Chromosome preparation of leukocytes cultured from human peripheral blood. Exp. Cell Res. 20: 613-616.

Nadler, C. F., and Lay, D. M. 1971. Chromosome of the Asian flying squirrel Petaurista petaurista (Pallas). Specialia 15: 1225 .

Nadler, C. F., and Sutton, D. A. 1967. Chromosomes of some squirrels (Mammalia-Sciuridae) from the genera Sciurus and Glaucomys. Experientia 23: 249.

Nowak, R. M. 1991. Walker's Mammals of the World. The Johns Hopkins University Press, Baltimore and London.

O’Brien, S. J., Menninger, J. C., and Nash, W. 2006. Atlas of Mammalian Chromosomes. John Wiley \& Sons, Hoboken, NJ.

Ono, T., and Obara. Y. 1994. Karyotype and Ag-NOR variations in Japanese vespertilionid (Mammalia: Chiroptera). Zool. Sci. 11: 473-484.

Ono, T., and Yoshida, M. C. 1998. Difference in the activity of rRNA genes localized on chromosomes 15 and 23 in orietal forest bat, Vespertilio superans. Chrom. Sci. 2: 129-134.

Oshida, T., Lin, L. K., Yanagawa, H., Kawamichi, T., Kawamichi, M., and Cheng, V. 2002. Banded karyotypes of the hairy-footed flying squirrel Belomys (Trogopterus) pearsonii (Mammalia, Rodentia) from Taiwan. Caryologia 55: $207-211$.

Oshida, T., and Obara, Y. 1993. C-band variation in the chromosomes of the Japanese giant flying squirrel, Petaurista leucogenys. J. Mammal. Soc. Jpn. 18: 61-67.

Oshida, T., Obara, Y., Lin, L. K., and Yoshida, M. C. 2000a. Comparison of banded karyotypes between two subspecies of the red and white giant flying squirrel Petaurista alborufus (Mammalia, Rodentia). Caryologia 53: 261-267.

Oshida, T., Satoh, H., and Obara, Y. 1992. A preliminary note on the karyotypes of giant flying squirrels Petaurista alborufus and P. petaurista. J. Mammal. Soc. Jpn. 16: 59-69.

Oshida, T., Yanagawa, H., Tsuda, M., Indue, S., and Yoshida, M. C. 2000b. Comparisons of the banded karyotypes between the small Japanese flying squirrel, Pteromys momonga and the Russian flying squirrel, P. volans (Rodentia, Sciuridae). Caryologia 53: 133-140.

Oshida, T., and Yoshida, M. C. 1999. Chromosomal localization of nucleolus organizer regions in eight Asian squirrel species. Chrom. Sci. 3: 55-58.

Schindler, A. M., Low, R. J., and Benirschke, K. 1973. The chromosomes of the New World flying squirrels (Glaucomys volans and Glaucomys sabrinus) with special reference to autosomal heterochromatin. Cytologia 38: 137-146.

Shida, T., Tsuchiya, K., Suzuki, H., Yanagawa, H., and Yoshida, M. C. 1999. Variation of the nucleolus organizer regions within the Japanese dormuse Glirulus japonicus Schinz (Rodentia, Muscardinidae). Chrom. Sci. 3: 29-32.

Stanyon, R. 1987. Banded karyotype of the 44-chromosome gibbons. Folia Primatol. 48: 56-64.

Rausch, V. R., and Rausch, L. R. 1982. The karyotype of the Eurasian flying squirrel, Pteromys volans (L.), with a consideration of karyotypic and other distinctions in Glaucomys spp. (Rodentia: Sciuridae). Proc. Biol. Soc. Wash. 95: 58-66.

Rønne, M. 1991. High-resolution banding: present aspects. Genet. Sel. Evol. 23: 49s-55s.

Rooney, D. E. 2001. Human Cytogenetics: Constitutional Analysis. Oxford University Press, Oxford.

Volleth, M. 1987. Differences in the location of nucleolus organizer regions in European vespertilionid bats. Cytogenet. Cell Genet. 44: 186-197.

Winking, H., Nielsen, T., and Gropp, A. 1980. Variable positions of NORs in Mus musculus. Cytogenet. Cell Genet. 26: 158-164.

Yunis, J. J. 1981. Mid-prophase human chromosomes. The attainment of 2000 bands. Hum. Genet. 56: 293-298.

Yunis, J. J., and Prakash, O. 1982. The origin of man: A chromosome pictorial legacy. Science 215: 1525-1530. 